\title{
Physico-chemical properties of blends of palm olein with other vegetable oils
}

\author{
By Bazlul Mobin Siddique, ${ }^{a}$ Anees Ahmad, ${ }^{\text {,* }}$ Mohamad Hakimi lbrahim, ${ }^{a}$ Sufia Hena, ${ }^{a}$ \\ Mohd Rafatullah ${ }^{\mathrm{b}}$ and Mohd Omar A. Ka .
}

\author{
${ }^{a}$ Division of Environmental Technology, School of Industrial Technology, Universiti Sains Malaysia, \\ 11800 Penang, Malaysia \\ ${ }^{b}$ Division of Bioresource Paper and Coatings Technology, School of Industrial Technology, Universiti \\ Sains Malaysia, 11800 Penang, Malaysia \\ ( ${ }^{*}$ Corresponding author: aneesahmad_ana@yahoo.com)
}

\section{RESUMEN}

Propiedades físico-químicas de mezclas de oleina de palma con otros aceites vegetales

Aceite de palma (oleína) fue mezclada con otros aceites comestibles para aumentar su aceptabilidad en el mercado en términos de descenso del punto de fusión y mejora de su almacenamiento. Las propiedades físico-químicas tales como viscosidad, densidad, comportamiento en la fusión, valor de peróxidos (PV), valor de saponificación (SV) e índice de yodo (IV) de cuatro diferentes mezclas binarias con cuatro aceites vegetales fueron evaluadas. La oleína de palma fue más estable frente a la rancidez que otros aceites. En la estabilidad frente la oxidación y el descenso del punto de fusión, la mezcla de oleína de palma/canola (PO/CO) fue mejor que las otras. Los termogramas del calorímetro diferencial de barrido (DSC) referidos al comportamiento de fusión de las mezclas indican algunos nuevos polimorfismos de los triglicéridos. Este estudio podría ayudar a las empresas que elaboran aceites a encontrar los aceites económicamente más viables para cocinar, con buenas propiedades nutricionales, así como con unas propiedades físico-químicas deseables.

PALABRAS CLAVE: Aceite de palma - Mezclas de aceites - Punto de fusión - Termograma.

\section{SUMMARY}

Physico-chemical properties of blends of palm olein with other vegetable oils.

Palm oil (olein) was blended with other edible oils for the enhancement of its market acceptability in terms of melting point depression and shelf life. The physico-chemical properties like viscosity, density, melting behavior, peroxide value (PV), saponification value (SV) and iodine value (IV) of four different binary blends with four vegetable oils were evaluated. Palm olein was found to be more stable against rancidity than the other oils. For the stability against oxidation and melting point depression the palm olein-canola $(\mathrm{PO} / \mathrm{CO})$ blend was found to be better than the others. The Differential Scanning Calorimeter (DSC) thermogram of the melting behavior of the blends traces some new polymorphs of the triglyceride. This study will help the oil producing industry to find out the most economically viable oil blends for cooking purposes, with maximum nutrition as well as desirable physico-chemical properties.

KEY-WORDS: Melting point - Oil blend - Palm oil Thermogram.

\section{INTRODUCTION}

Vegetable oil is an important and widely used lipid source for our everyday food products. Its application is increasing day by day for food purposes and for the manufacturing of a number of toiletry products. However, some vegetable oils are not up to standards to meet consumer satisfaction in terms of their physico-chemical properties or for the texture and stability of the food products (ReyesHernández et al., 2007). Recently, palm oil has become the second most consumed oil all over the world with a competitive price compared to other edible oils. However, due to its high melting point, it is not gaining due status in spite of being rich in natural antioxidants, vitamins, high oxidative stability and having a long self life (Edem, 2002). Palm oil is also rich in $\beta$-carotene which helps to prevent liver and lung cancer (Murakoshi et al., 1992).

The food value of the edible lipids also depends on chemical properties like iodine value, peroxide value, $\mathrm{p}$-anisidine value, acidity etc, as well as on some physical properties like solidification temperature, color, appearance etc. To enhance the oxidative stability and plasticity of oils hydrogenation was developed. But it is now a well established fact that it produces trans fatty acids which have harmful effects on human health. Furthermore, such a process increases the melting point of oils which is undesirable especially for salad dressing, desert making and for confectionary based food (Shibasaki and Yamane, 2000). These oils solidify in the food under cold conditions and thus discourage the consumer from using these oils. In fact it degrades the food's aesthetic value too. To impede the solidification of sesame oil at low temperatures, Shibasaki and Yamane, (2000) used lipase catalyzed self-interesterifiction and found that the melting temperature of the oil is reduced substantially. But the problem with the interesterification reaction is that it produces free fatty acids too. Depression of the melting point of the oils by esterification and by ozonization is helpful for usings as biofuel as it is good for producing appropriate fatty acid esters (Soriano et al., 2006). To decrease the melting point of edible oil and to maintain 
its aesthetic quality, blending is a good and feasible option and thus the quality of the oils can be improved. The oxidative stability, iodine value and peroxide value can be improved in this way to get good and desirable blends which will help to provide precise stability data.

In oil research, the viscosity of the oil is a very important factor. In food it draws the interest of the customer, and oils with lower values of viscosity, density and low melting point are highly desirable to consumers. In order to design an advanced technological process it might be an important parameter. In biofuel research, these parameters are necessary to run the engine in a cold climate. Viscosity is a physical and inherent property of the fluid which bared a layer of a liquid to flow in relation to another one. Since oils are mixtures of Triglycerides (TGs), viscosity will depend on the nature of the TGs presents in the oil. The viscosity might change due to the different arrangement of the fatty acids on the glycerol backbone of the triglyceride molecule. Therefore, viscosity is related to the chemical properties of the oils such as chain length and saturation/unsaturation. It has been reported that viscosity decreases with an increase in unsaturation and increases with high saturation and polymerization so therefore relates to the melting point of the oils as well (Kim et al., 2010). Viscosity also depends on sheer stress and temperature. Sheer stress does not have much effect on the storage of the oils which are used for edible purposes but the temperature does affect it. Oil with sustainable viscosity can be obtained by blending it with some other oils which is an innovative idea because it allows the blends to remain free from any added chemicals. It will also help to get the oils of a desired quality that is good for human health. As low melting oils contain more unsaturation they are very prone to oxidation and become rancid easily. Oils with lower melting points become rancid due to the presence of unsaturation in them. Furthermore, the rancidity of oils depends on the period, temperature and process of storage (Aidos et al., 2002; Tan and Man, 2002). Rancidity alters the sensory and nutritive value of the oil and also threatens food safety (Wu and Nawar, 1986). Antioxidants play an important role in hindering the oxidative degradability of oils. Tawfik et al. (1999) studied the peroxide value and stability of oils and concluded that the presence of Vitamin $E$ (tocopherol) enhances the oxidative stability of oils against rancidity and probably for the same reason palm oil shows a greater stability compared to other vegetable oils.

The main aim of this work is to find the change in physical and chemical properties of vegetable oils such as palm olein (PO), canola oil (CO), sunflower oil (SF), soybean oil (SO) when they are blended with one another in different mixing ratios. It is also aimed at finding a blend of oxidatively stable palm olein with low melting points by adding vegetable oils with high degrees of unsaturation.

\section{MATERIALS AND METHODS}

\subsection{Oil samples}

Refined, bleached, deodorized (RBD) palm olein (PO), canola oil (CO), sunflower oil (SF) and soybean oil (SO) were purchased from the local super market. The samples were kept in the refrigerator below $4^{\circ} \mathrm{C}$ for storage. They were taken out of the refrigerator well in advance, prior to study, to attain thermal equilibrium with the ambient temperature of the lab. Oil blends were prepared by mixing palm olein with blending oil $(\mathrm{w} / \mathrm{w})$ in different ratios ranging from 10:90 to 90:10. The mixtures were stirred in a magnetic stirrer for 20 minutes for homogenization. All chemicals and reagents used were of analytical grade.

\subsection{Methods}

\section{Density and viscosity}

The density of the oils was determined by a mass over volume measurement. The viscosity of the oils and their blends was determined by BROOKFEILD DVII + Pro viscometer at a constant shear rate at three different temperatures which were controlled by a microprocessor assisted water bath using spindle S51.

\section{Melting point study}

The melting point of the oils and their blends were determined using a Differential Scanning Calorimeter (DSC) (PerkinElmer, Pyris 1, Version 5.00.02, USA). The oils and the blends were homogenized and filtered through filter paper and then heated at $50{ }^{\circ} \mathrm{C}$ to demolish all fat crystal remains and cooled again to room temperature. The samples (each about $16 \mathrm{mg}$ ) were then taken to the hermetically sealed aluminum pans for analysis by DSC operating in the temperature of $-50^{\circ} \mathrm{C}$ to $50^{\circ} \mathrm{C}$ at a heating rate of $10^{\circ} \mathrm{C}$ per minute, associated with purge liquid nitrogen gas.

\section{Peroxide value}

The Peroxide values were determined according to the official method No. 965.33 of the Association of Official Analytical Chemist (AOAC). The sample $(0.5 \mathrm{~g})$ was taken to the nearest of $0.1 \mathrm{mg}$ in a conical flask, $30 \mathrm{~mL}$ of the acetic acid and chloroform (mixture 2:3) were added to it followed by $0.5 \mathrm{~mL}$ of a saturated potassium iodide solution. After 1 minute of occasional shaking, $30 \mathrm{~mL}$ of distilled water were added. It was titrated slowly with a 0.01 $\mathrm{M} \mathrm{Na}_{2} \mathrm{~S}_{2} \mathrm{O}_{3}$ solution with vigorous shaking until the disappearance of the yellow color, $0.5 \mathrm{~mL}$ of $1 \%$ starch indicator was added and titration continued till until the blue color had just disappeared. Each test was done in duplicate and a blank test was carried out. The PV of the oils and their blends was determined in 8 week intervals while all the oil 
samples were kept in uncovered beakers at room temperature during this time.

\section{Saponification value}

SVs were determined by the AOAC official Method No. 920.160. A $0.1 \mathrm{~N} \mathrm{KOH}$ solution was prepared with $95 \%$ ethanol and distilled. $5 \mathrm{~g}$ of oil sample were weighed in a conical flask, the flask was connected to an air condenser and boiled until the oil was completely saponified, cooled and titrated with $0.5 \mathrm{M} \mathrm{HCl}$ using phenolphthalein as indicator.

\section{lodine value}

The AOAC Official Method 993.20 (Wijs method) was used to determine the lodine values. The sample was taken nearest to $0.001 \mathrm{~g}$ according to its IV and was dissolved in $15 \mathrm{~mL}$ of $3: 2 \mathrm{v} / \mathrm{v} \mathrm{CH} \mathrm{CH}_{3} \mathrm{COOH}$ and cyclohexane solution, $25 \mathrm{~mL}$ of Wijs solution was added and kept undisturbed in the dark following the IV scale, after that time it was titrated with a $0.1 \mathrm{M}$ $\mathrm{Na}_{2} \mathrm{~S}_{2} \mathrm{O}_{3}$ solution.

\section{RESULTS AND DISCUSSION}

\subsection{Density and viscosity}

The densities of the binary blends like palm oleinsoybean oil, palm olein-sunflower oil and palm oleincanola oil were found to be comparable to those of the pure blending oils as shown in Table 1 . The viscosity of the palm olein was found higher among these four vegetable oils used for blending, while viscosity decreased with an increase in temperature. An increase in temperature enhances the movements of the molecules and reduces intermolecular forces so the layers of the liquid easily pass over one another and thus contribute to the reduction of viscosity. This phenomenon is also verified by other researchers since oil viscosity depends on molecular structure and decreases with the unsaturation of fatty acids (Kim et al., 2010). It may be due to the $\pi$ bonds that make the bonding more rigid and rotation between $\mathrm{C}-\mathrm{C}$ bonds becomes more strenuous. Also, the extended chain makes the flow easier and reduces viscosity (Santos et al., 2005). It is also probably because of less friction among the acid chains. It was observed that viscosity decreases linearly with the increase in low viscous oil portion in the blends at 23 and $33^{\circ} \mathrm{C}$; but at $43^{\circ} \mathrm{C}$ the viscosity of the blends decreases more with a slight deflection, especially for the palm-soybean oil blend. This might be due to the presence of fat crystals that coalesce together and need more time for destruction while they increases the friction between the layers and this results in a sharp increase in viscosity. (Vaclavik \& Christian, 2003; Graef et al., 2008)

\subsection{Melting point}

The experimental results showed a substantial decrease in the melting point of the palm olein when blended with other oils. The higher portion of the other low melting point oil blended with palm olein results in a further decrease in the melting point of the blends. By blending with these oils the portion of the unsaturated fatty acids increased in the blends but these fatty acids do not take part in any chemical change in the oils and do not interact with triacylglycerol as they are of similar chemical composition (Benjumea et al., 2008). Any change in the chemical composition of the molecular species of triacylglycerol would have changed the physical properties of the blends as the physical and chemical properties of vegetable oils are the function of triglycerides in fatty acids (Tan and Man, 2002; Fogila et al., 1993). However, the entire physical properties of the oils and the blends did not change and thus the above statements were found true. The DSC thermogram for pure palm olein produced more than one peak as shown in Figure 1(a), which might be due to the presence of impurities such as a trace stearine fraction. The melting behavior of the oils varies due to the different characteristics and composition of fatty acids in terms of triglycerides (Fasina et al., 2008). According to Man and Swe, (1995) the low temperature peaks for heating in the thermogram represent $\beta_{2}^{\prime}$ and $\alpha$ and the high temperature peaks stand for $\beta^{\prime}$, and $\beta_{1}$ polymorphs. But for pure palm oil, only the two peaks are visible, which may be due to the polymorphs of $\beta_{2}^{\prime}$ and $\alpha$ as both of them occurred at relatively high temperatures. The thermogram of the blends shown in Fig. 1(a) and 1(b) indicate a regular peak shift towards the low melting region and so does the $\hat{I}_{2}^{2} \Re$ polymorph. The rest of the peaks formed [Figure 1(c) and 1(d)] upon consecutive blending results in complicated polymorphs by association of two existing polymorphs or sometimes in between them (Man and Swe, 1995).

\subsection{Peroxide value (PV)}

The peroxide value was also found to increase with the storage time, temperature and contact with air of the oil samples. The PVs were found different for different oils. The initial PV was found to have occurred around 2.5 to 5 meq $\mathrm{O}_{2} / \mathrm{kg}$ oil which indicates a relatively good quality of these oils but after exposure to light and air at room temperature the PV increased to a maximum value of $70 \mathrm{meq}$ $\mathrm{O}_{2} / \mathrm{kg}$ oil for soybean- palm blend. However, for canola-palm blend it was found to be as low as 40 meq $\mathrm{O}_{2} / \mathrm{kg}$ oil. The initial value and after 3 weeks the PV for palm olein-canola blends was found to be almost the same, although after 8 weeks it was lower than the others (Figure. 2). Probably exposure to the light and air triggered oxidation which enhanced its peroxide value. This indicates that the natural antioxidants in both palm and canola oil hinder the oxidation process considerably in this oil blend compared to the others. Furthermore, the storage of the samples at ambient temperature caused the PV to increase rapidly due to the contact with air and light. The trace amounts of the heavy 
Table 1

Rheological parameters for pure blenders and their binary blends.( Koh etal., 2009)

\begin{tabular}{|c|c|c|c|c|}
\hline \multirow{2}{*}{ Pure Oils } & \multirow{2}{*}{$\begin{array}{c}\text { Density }(\mathrm{g} / \mathrm{mL}) \\
\text { Room Temp. }\left({ }^{\circ} \mathrm{C}\right)\end{array}$} & \multicolumn{3}{|c|}{ Viscosity (cP) } \\
\hline & & $23^{\circ} \mathrm{C}$ & $33^{\circ} \mathrm{C}$ & $43^{\circ} \mathrm{C}$ \\
\hline Palm olein & 0.917 & 79.70 & 63.20 & 36.70 \\
\hline Soybean oil & 0.931 & 61.10 & 38.60 & 29.30 \\
\hline Sunflower oil & 0.932 & 62.00 & 44.00 & 30.30 \\
\hline Canola oil & 0.917 & 67.10 & 53.10 & 32.40 \\
\hline \multicolumn{5}{|l|}{ Oil Blenders } \\
\hline \multicolumn{5}{|c|}{ Palm olein : Soybean oil } \\
\hline \multicolumn{5}{|l|}{ Mixing ratio } \\
\hline $10: 90$ & 0.909 & 60.80 & 42.50 & 30.10 \\
\hline $20: 80$ & 0.909 & 62.10 & 44.10 & 30.60 \\
\hline $30: 70$ & 0.909 & 63.90 & 44.50 & 33.70 \\
\hline $40: 60$ & 0.914 & 68.10 & 46.60 & 32.60 \\
\hline $50: 50$ & 0.925 & 69.10 & 46.60 & 32.90 \\
\hline $60: 40$ & 0.919 & 71.70 & 48.40 & 33.90 \\
\hline $70: 30$ & 0.908 & 72.80 & 49.40 & 34.70 \\
\hline $80: 20$ & 0.920 & 75.10 & 50.20 & 37.50 \\
\hline $90: 10$ & 0.919 & 76.60 & 52.00 & 34.70 \\
\hline \multicolumn{5}{|c|}{ Palm olein : Sunflower oil } \\
\hline \multicolumn{5}{|l|}{ Mixing ratio } \\
\hline $10: 90$ & 0.906 & 63.70 & 43.20 & 31.10 \\
\hline $20: 80$ & 0.921 & 65.50 & 44.00 & 31.30 \\
\hline $30: 70$ & 0.910 & 66.30 & 45.30 & 31.60 \\
\hline $40: 60$ & 0.914 & 67.60 & 45.80 & 32.40 \\
\hline $50: 50$ & 0.905 & 70.40 & 45.80 & 33.70 \\
\hline $60: 40$ & 0.914 & 72.50 & 47.10 & 34.70 \\
\hline $70: 30$ & 0.911 & 73.50 & 48.70 & 35.20 \\
\hline $80: 20$ & 0.902 & 75.30 & 47.40 & 36.00 \\
\hline $90: 10$ & 0.933 & 76.40 & 52.00 & 34.70 \\
\hline \multicolumn{5}{|c|}{ Palm olein : Canola oil } \\
\hline \multicolumn{5}{|l|}{ Mixing ratio } \\
\hline $10: 90$ & 0.907 & 66.50 & 45.60 & 32.90 \\
\hline $20: 80$ & 0.907 & 68.30 & 46.10 & 32.60 \\
\hline $30: 70$ & 0.908 & 69.90 & 46.30 & 33.40 \\
\hline $40: 60$ & 0.915 & 70.40 & 46.10 & 33.90 \\
\hline $50: 50$ & 0.918 & 71.50 & 48.90 & 35.50 \\
\hline $60: 40$ & 0.917 & 72.80 & 50.00 & 35.00 \\
\hline $70: 30$ & 0.917 & 74.00 & 49.70 & 35.20 \\
\hline $80: 20$ & 0.918 & 76.60 & 51.00 & 35.70 \\
\hline $90: 10$ & 0.919 & 77.40 & 52.30 & 35.70 \\
\hline
\end{tabular}




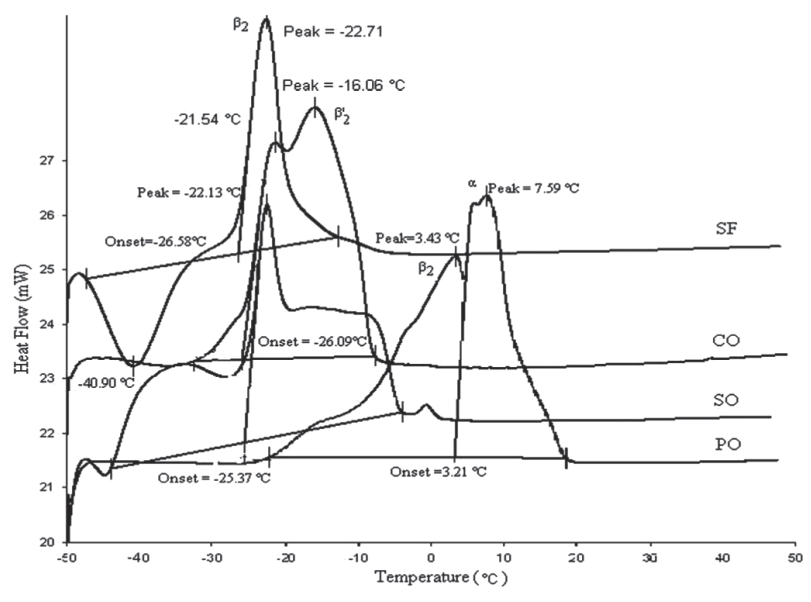

Figure 1 (a)

DSC Thermogram (a) pure oils, (b) oil blends (20:80), (c) oil blends (50:50) and (d) oil blends (80:20).

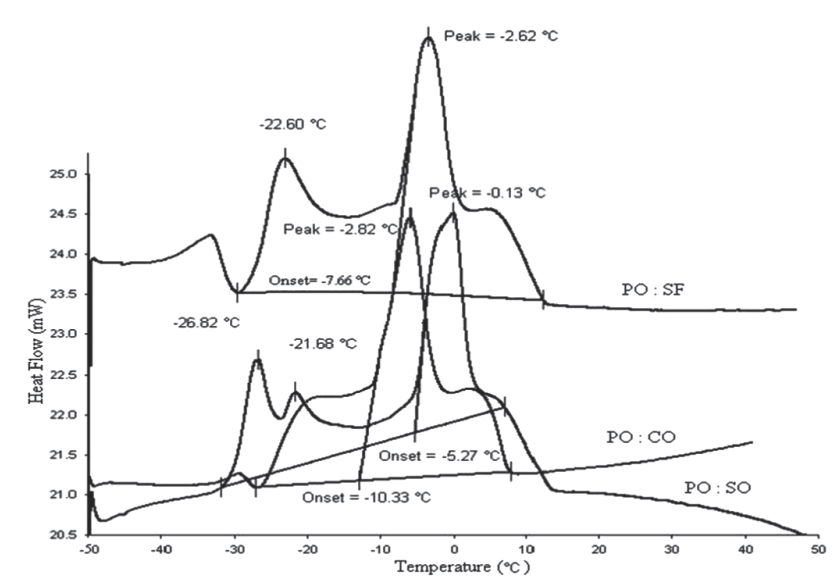

Figure 1 (c).

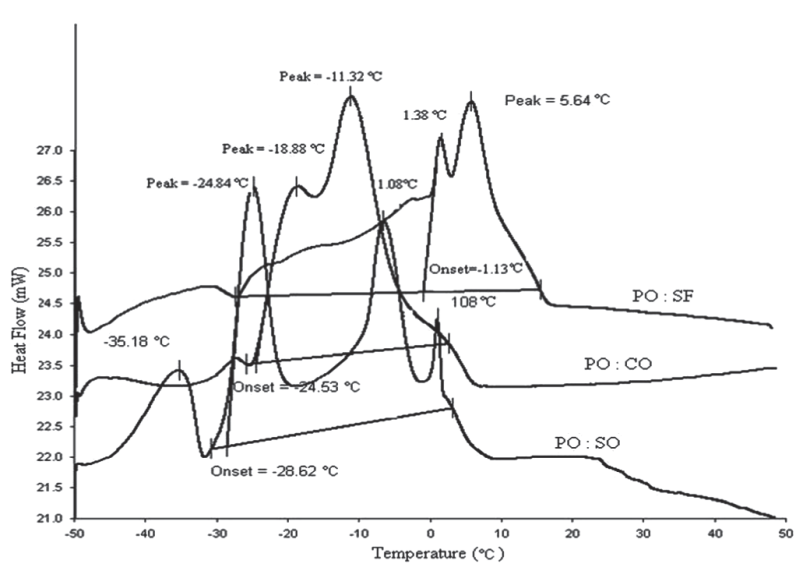

Figure $1(b)$.

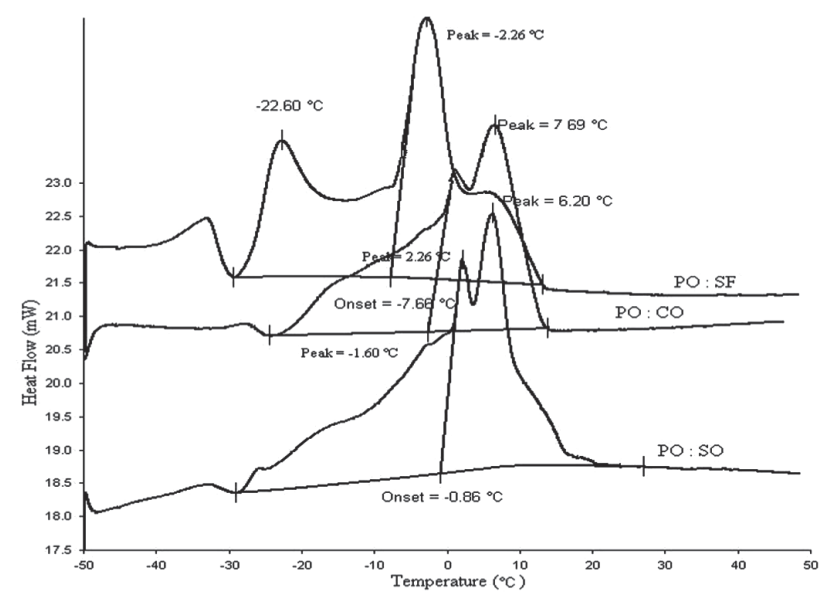

Figure 1 (d).

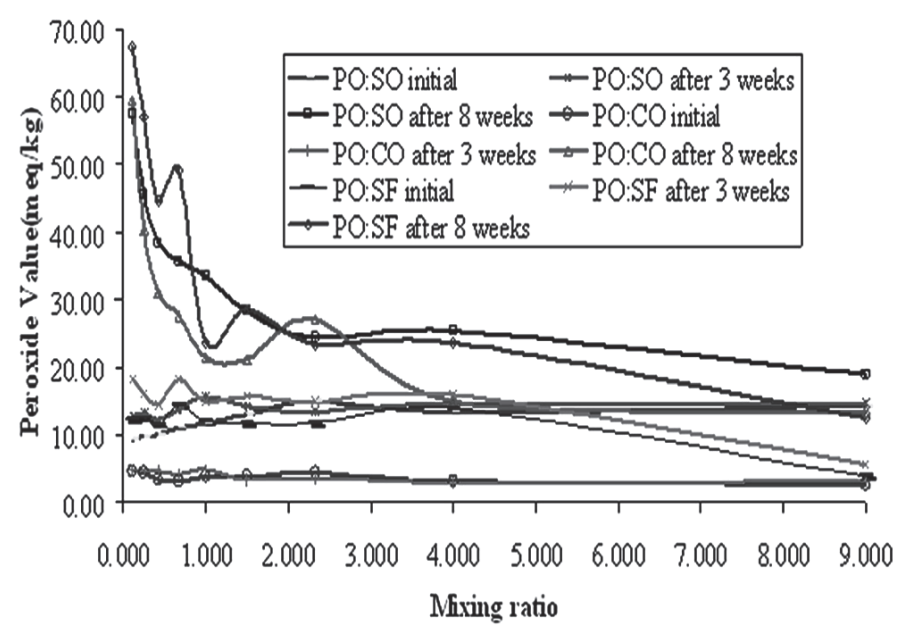

Figure 2.

Aging effect on peroxide value of palm olein blended with other oils. 
metals in the oils might also positively affect the enhancement of PV.

\subsection{Saponification value (SV)}

Similar to $\mathrm{PV}$, the saponification value also indicates deterioration of the oils. The saponification value was found to increase with storage time. This trend explains that with the long storage of these oils, fatty acids are likely to be formed which increase the SV. This also indicates that these long stored degraded oils can play a favorable role in producing soaps and toiletry products profitably.

\section{5. lodine value (IV)}

All the oils purchased were RBD and their initial IV was found to be very high. The IV of the oils of palm olein, soybean, sunflower and canola were found to be $67,202,197$, and 226 respectively. This is an indication of high saturation in these oils and thus they become more vulnerable to oxidation. The IV of an oil does not indicate the position of the double bonds or amount of olefinic carbon but rather it provides an overall status of unsaturation of the oils so it is not possible to point out the position of double bond(s) which are more susceptible to oxidation (Knothe and Dunn, 2003). Although the palm super olein has a bright transparent color, a bit similar to other oils, due to its self antioxidation capability its IV did not change like those of the other oils after extended exposure to air and light which indicates that the palm olein is more stable among the others and its quality remains unchanged. As anticipated, the IVs for the blends of the oils were not at all similar. At the initial stage, all oil the blends were found to have similar IVs. However, it was anticipated that the IV would decrease with exposure to light and air and would follow the ratio of the percentage of the mixture of two oils due to the decrease in unsaturation; but contrary to our belief, an increasing trend was found for IV. This is highly unlikely and the reason behind it might be oxidation of oil constituents and the formation of peroxides which might be enhanced by the bacterial effect along with air and light exposure. Among all blends palm olein-sunflower blends show more consistency between initial and final IVs. The phenomenon of the increasing trend in IV indicates a risk to the consumer health instead of increasing unsaturation. For the other blends the IV also increased with the time. For the same reason, to maintain and preserve oil quality, it is advisable to keep it in cool places in airtight, dark containers flushed with nitrogen and the container should be glass, which is better than PVC or more simple container ( Kaul et al., 2009).

\section{CONCLUSIONS}

The quality and properties of the oils and blends were evaluated through this study using different parameters. Palm olein was found to be the most stable against rancidity and oxidation. It has the natural potential of maintaining those important parameters within established limits. Though for the other oils these phenomena are almost the same, for the palm olein-canola blend they were found to have more resistance against oxidation and melting point, which was also found to be lower for this blend, followed by palm olein-soybean and palm olein-sunflower blends. For all oil blends the IV has the same unusual tendency to increase, which was supposed to decrease but due to the formation of peroxide the value was found higher. The viscosity, like all other Newtonian fluids, decreased with an increase in temperature due to the destruction of the solidified oil crystals, as the blends are the simple mixing of two oils in different proportions, it appears to be an average property of the mixture in the blends. It is a sign of the manipulation of the fatty acid profile inherited by the oils and not the formation of any new component. This study will help the oil producing industry to find the most economically viable oil blends for cooking purposes, with maximum nutrition as well as desirable physico-chemical properties. Thus blending is a good choice by which we can manufacture edible oils of good characteristics and ensure their quality. The food value of the oils and blends can also be predetermined to provide the safest food fo consumers

\section{ACKNOWLEDGEMENTS}

The financial assistance by Ministry of Science and Innovation (MOSTI) under science fund (Grant No. 305/PTEKIND/613310) and research facilities provided by Universiti Sains Malaysia are gratefully acknowledged.

\section{REFERENCES}

Aidos I, Lourenclo S, Padt A, Luten J B, Boom RM. 2002. Stability of Crude Herring Oil Produced from Fresh Byproducts: Influence of Temperature during Storage. J. Food Sci. 67, 3314-3320.

Benjumea P, Agudelo J, Agudelo A. 2008. Basic properties of palm oil biodiesel-diesel blends. Fuel. 87, 2069-2075.

Che Man YB, Swe PZ. 1995. Thermal analysis of failed batch palm oil by differential scanning calorimetry. J. Am. Oil Chem. Soc. 72, 1529-1532.

Edem DO. 2002. Palm oil: Biochemical, physiological, nutritional, hematological and toxicological aspects: A review. Plant Foods for Human Nutrition (Formerly Qualitas Plantarum) 57, 319-341.

Fasina OO, Craig-Schmidt M, Colley Z, Hallman H. 2008. Predicting melting characteristics of vegetable oils from fatty acid composition. LWT -- Food Sci. Technol. 41, 1501-1505.

Foglia T, Petruso K, Feairheller S. 1993. Enzymatic interesterification of tallow-sunflower oil mixtures. J. Am. Oil Chem. Soc. 70, 281-285.

Graef VD, Goderis B, Puyvelde PV, Foubert I, Dewettinck, K. 2008. Development of a rheological method to 
characterize palm oil crystallizing under shear. Eur. J. Lipid Sci. Technol. 110, 521-529.

Jaswir I, Che Man Y, Kitts D. 2000. Optimization of physicochemical changes of palm olein with phytochemical antioxidants during deep-fat frying. $J$. Am. Oil Chem. Soc. 77, 1161-1168.

Kaul S, Goyal HB, Bhatnagar AK, Gupta AK. 2009. Effect of ageing on quality of jojoba oil from Indian locations. Industrial Crops and Products 29, 102-107.

Kim J, Kim DN, Lee SH, Yoo S.-H, Lee S. (2010). Correlation of fatty acid composition of vegetable oils with rheological behaviour and oil uptake. Food Chem. 118, 398-402.

Knothe G, Dunn R. 2003. Dependence of oil stability index of fatty compounds on their structure and concentration and presence of metals. J. Am. Oil Chem. Soc. 80, 1021-1026.

Murakoshi M, Nishino H, Satomi Y, Takayasu J, Hasegawa T, Tokuda H, Iwashima A Okuzumi J, Okabe H, Kitano $\mathrm{H}$, et al. 1992. Potent Preventive Action of \{alpha\}Carotene against Carcinogenesis: Spontaneous Liver Carcinogenesis and Promoting Stage of Lung and Skin Carcinogenesis in Mice Are Suppressed More Effectively by \{alpha\}-Carotene Than by beta Carotene. Cancer Res. 52, 6583-6587.

Reyes-Hernández J, Dibildox-Alvarado E, Charó-Alonso M, Toro-Vazquez J. 2007. Physicochemical and Rheological Properties of Crystallized Blends Containing trans -free and Partially Hydrogenated Soybean Oil. J. Am. Oil Chem. Soc. 84, 1081-1093.
Santos JCO, Santos IMG, Souza AG. 2005. Effect of heating and cooling on rheological parameters of edible vegetable oils. J. Food Eng. 67, 401-405.

Shibasaki H, Yamane T. 2000. Avoidance of Solidification of Sesame Oil at Low Temperature by Selfinteresterification with Immobilized Lipase. Biosci. Biotechnol., Biochem. 64, 1011-1015.

Soriano NU, Migo VP, Matsumura M. 2006. Ozonized vegetable oil as pour point depressant for neat biodiesel. Fuel. 85, 25-31.

Tan CH, Ghazali HM, Kuntom A, Tan CP, Ariffin AA. 2009. Extraction and physicochemical properties of low free fatty acid crude palm oil. Food Chem. 113, 645-650.

Tan CP, Man YBC. 2002. Comparative differential scanning calorimetric analysis of vegetable oils: I. Effects of heating rate variation. Phytochem. Anal. 13, 129-141.

Tawfik MS, Huyghebaert A. 1999. Interaction of packaging materials and vegetable oils: oil stability. Food Chem. 64, 451-459.

Vaclavik VA, Christian EW. 2003. Fat and Oil Products. In D. R. Heldman (Ed.), Essentials of Food Science, Springer Science + Business Media, LLC. New York, USA. pp. 280-281.

Wu PF, Nawar W. 1986. A technique for monitoring the quality of used frying oils. J. Am. Oil Chem. Soc. 63, 1363-1367. 